\title{
O QUE OS BEBÊS SABEM? UM MODO DIFERENCIADO DE PENSÁ-LOS
}

\author{
Gerson Carneiro de Farias \\ Mestre em Educação pela UERJ, Rio de Janeiro. Professor da Faculdade de Educação Física da Universidade Federal de Goiás.
}

\begin{abstract}
Resumo
O objetivo deste artigo é apresentar um modo diferenciado de pensar o bebê: um ser que é reflexo, contudo cortical também; que está motivado para a comunicação com os outros; que reage à luz, ao som e à voz da mãe; que sente e sabe que existe a partir do fim do segundo trimestre de gestação.

Palavras-chave: bebê - intersubjetividade - teoria da mente - comportamento visual - auditivo - linguagem e aprendizagem
\end{abstract}

\section{Introdução}

A

ntes de responder esta questão, é preciso fazer dois esclarecimentos. O primeiro é que não tenho a resposta para o que os bebês sabem. Então, por que a pergunta sobre o que os bebês sabem? É muito simples; quando estamos diante de uma questão, podemos não saber a resposta, mas temos algum discernimento, algum entendimento sobre ela. Acumulamos um conhecimento crescente sobre a questão e temos uma vaga idéia da resposta. Cada idéia deste texto pode revelar-se incerta, mas isso já seria um progresso, porque as velhas idéias sobre o bebê ser somente reflexo, por exemplo, e não possuir a capacidade de se comunicar eram muito sem graça. $\mathrm{O}$ segundo esclarecimento é que os princípios do desenvolvimento humano são muito complexos e, hoje, estão ainda em pesquisa; portanto, não se descobriu ainda o que os bebês sabem na íntegra, mas se tem uma boa idéia do que eles possam estar pensando. Nenhuma das idéias no texto é minha, apenas comungo com elas. Selecionei, de muitos es- tudiosos, pensamentos que parecem oferecer um entendimento diferenciado a respeito de como os bebês se comportam; que se ajustam às pesquisas recentes; predizem fatos novos e são coerentes com seus resultados. Afinal, não é este o objetivo da atividade científica: aprender a dominar as causas e os efeitos dos fenômenos que se observam; explicá-los, predizê-los, controlá-los e transformá-los?

Nesse sentido, o objetivo deste texto é tecer essas idéias de forma coesa, utilizando o conceito de Intersubjetividade e de Teoria da Mente, num primeiro momento, isto é, o entrelaçamento desses dois conceitos. Num segundo momento, identificar o comportamento visual e auditivo dos bebês. Até porque esses sentidos são considerados nobres. São eles que organizam os demais sentidos no organismo. A visão assume o papel de um órgão coordenador, regulador e controlador. É nas relações neurosensoriais entre visão e audição, entre a visão e o sentido tátil-cinestésico, que as aquisições básicas de motricidade, linguagem, competência social e cognição vão se 
desenvolvendo na criança. Desse modo, nos propomos a discorrer sobre o comportamento dos bebês, sua relação com a visão, com a audição, sua atitude reflexa e cortical. E, num terceiro momento, fazer algumas considerações sobre a sua linguagem e as janelas de aprendizagem.

\section{Intersubjetividade e teoria da mente}

Intersubjetividade é a capacidade psicológica inata para reconhecer e comunicar-se com os estados psicológicos de outros indivíduos (FIAMENGHI, 2003). Exemplificando, quando o bebê sorri, o pai pode se emocionar com esta ação. Ele pensa que o bebê sorri porque entende que ele gosta de sua presença. Esta ação, com o tempo, passa a ser verdadeira, ao dizer para o bebê: "você olhou para mim", retribuindo o sorriso e olhando para o bebê. Mais tarde o bebê atenderá a uma solicitação com o sorriso e o olhar. Por sua vez, o bebê tem consciência da atitude do pai (NUNES, 1992). A compreensão desse processo pelo bebê chama-se Teoria da Mente. Em outras palavras, o bebê tenta identificar a maneira como o conhecimento e as emoções do pai em particular afetam as suas ações e por que as pessoas da família diferem umas das outras tão marcadamente em relação a pensamentos, sentimentos e intenções, ainda que sejam nas mesmas situações (BERGER, 2000).

O bebê nasce provido para o amor. Por isso as palavras de carinho, as histórias contadas e as canções que o bebê ouve durante a gravidez podem contribuir para prepará-lo para esse amor. Após o nascimento, esse processo continua por meio de gestos de carinho, trocas de olhar e brincadeiras entre a criança, a mãe, o pai e as pessoas próximas. A família tornase a sede desse amor. Os efeitos do amor são sentidos em qualquer idade. Qualquer bebê recém-nascido reconhece amor. Sua ausência pode causar danos no bebê. Lewis e colaboradores (2001, p. 188-189) afirmam que

\begin{abstract}
o amor, ou a falta dele, pode mudar o cérebro para o resto da vida. Nós costumávamos acreditar que o sistema nervoso chegaria à maturidade seguindo apenas as instruções contidas no DNA. Hoje sabemos que as experiências são cruciais para um desenvolvimento saudável do sistema nervoso. O amor está com toda certeza entre as mais significativas das experiências.
\end{abstract}

Estudos nos mostram que os recém-nascidos são precocemente responsivos à mãe: sorriem, estabelecem contato visual, ficam atentos quando ela fala, chegam a imitar as expressões faciais da mãe. Nessas atitudes a criança pega o estado mental do adulto, principalmente nas funções protodeclarativas de apontar, dar e receber que contribuem para a aquisição de sua fala futura (NUNES, 1992).

Todo ato social na criança começa a ser compreendido e expresso por meio do gesto. Apontar, evocar, chamar a atenção, pegar e outros, começam por substituir o choro para induzirem, posteriormente, à emergência da significação social que termina na palavra. A criança usa os gestos exatamente porque para ela ilustrar objetos e ações ainda é difícil de verbalizar. É a melodia do gesto que socializa a forma de comunicação não-verbal e verbal. $\mathrm{O}$ movimento enriquece a linguagem e o corpo acolhe a palavra (FONSECA, 1998). Em suma, o gesto é um processo de linguagem da sensibilidade. A criança usa de estratégias psicológicas, podendo chorar quando não está assim tão faminta e com frio ou deixa de sorrir até conseguir o que quer; como parte interessada, despende todas as forças pelos seus interesses como único recurso à sua disposição - a graciosidade (PINKER, 2001). Guiados por Piaget (1973), a maioria dos desenvolvimentistas pensava que a criança era incapaz de fazer isto.

Os conceitos de Intersubjetividade e Teoria da Mente são fundamentais para a compreensão do desenvolvimento infantil, pois nos auxiliam a perceber o recém-nascido como um 
ser motivado, dotado de vontade e não um ser caótico com comportamentos compostos apenas por reflexos. Estamos, apenas agora, começando a compreender: que os bebês possuem uma vida mental, que estão particularmente bem preparados para a vida social e desejosos de participar dela.

Desse modo, a intersubjetividade nos leva à compreensão das relações do bebê para com o mundo. E a teoria da mente nos leva a compreensão de que o bebê capta o estado mental de seus pais: as emoções, percepções, intenções e pensamentos deles. Dito de outro modo, a teoria da mente é a capacidade de pensar sobre os estados mentais de outra pessoa e formar teorias sobre a maneira como elas pensam.

\section{O comportamento visual}

Nesse sentido, o comportamento visual desempenha um papel primordial no desenvolvimento motor e lingüístico do ser humano, sem o qual a sua caminhada não seria alcançada (BRONOWSKY, 1986). No bebê, alguns reflexos visuais já estão presentes desde o sétimo mês de gestação, mostrando que nesta época de vida uterina, mediante as vias ópticas, já acontece uma reação pupilar primitiva e a criança reconhece a luz. O estímulo segue até ao córtex e se tem uma resposta em forma de constituição visual. Por exemplo, se você acender uma luz forte na barriga de uma gestante, o bebê reage tentando fugir.

Entre o sétimo mês de vida fetal até o terceiro mês de vida fora do útero, aparece o fenômeno dos olhos de boneca japonesa: quando se rota, flexiona ou estende-se a cabeça da criança, seus olhos permanecem fixos, não acompanham o movimento da cabeça, parecendo deslocar-se em sentido contrário. Este reflexo é progressivamente inibido, isto é, suprimido ou diminuído da atividade duma parte do organismo, por efeito da excitação nervosa, e logo substituído pelo reflexo de fixação ocular que marca a capacidade desta criança fixar seu olhar após um mês do nascimento (CORIAT, 1991).

Gallahue e Ozmun (2003, p. 172) afirmam que "o periodo de inibição desaparece se o reflexo for exercitado"; e este processo de inibição pode ocorrer até o quarto mês de vida (SCHWARTZMAN, 2003). Na gestação, a partir do sexto mês, o bebê já tem o reflexo palpebral à luz. Diante de uma luz intensa ele fecha os olhos. Após, ele tem o reflexo que chamamos olho-pescoço: diante de uma luz intensa ele fecha os olhos e joga a cabecinha para trás. Obviamente, são mecanismos de defesa com os quais essa criança já conta desde a metade da gestação. Já evidencia reflexos palpebrais ao som.

O curioso é que a partir do sexto e sétimo meses de gestação a criança arregala os olhos ao ouvir o som como se estivesse prestando atenção ao que está acontecendo. É como se fosse um sinal de alerta. Quando há sons intensos, ela fecha os olhos, o que provavelmente também é um reflexo de defesa. É a partir daí que os reflexos têm inúmeras explicações e inter-relações: reflexos ciliares, corneanos, naso-palpebrais etc. Estes reflexos estão enraizados no processo de maturação do bebê. Eles estão intimamente ligados entre si; se isolados, tornam-se uma abstração; se desenvolvem, se modificam e se adaptam às circunstâncias do momento, do meio, da saúde geral da criança, da sua idade e do seu temperamento (CORIAT, 1991).

Assim, uma série de reflexos já está presente, sendo quase todos a partir da metade da vida fetal. Alguns permanecem, fazendo parte da vida do bebê, outros se modificam e outros desaparecem. A carga presente desses reflexos é pequena, mas o suficiente para piscar, por exemplo, se um objeto se dirige a seu rosto, como se defendendo da quantidade de brilho daquele objeto. E o comportamento cada vez mais se organiza e fica complexo, numa progressão do simples, desorganizado e inabilidoso para altamente organizado, complexo e habilidoso (BARELA, 2003). O neo- 
nato, já na sala de parto, dirige a cabeça para uma fonte de luz moderada e afasta a cabeça de uma fonte de luz intensa (SCHWARTZMAN, 2003).

Entre quatro e sete semanas de nascido, o bebê já estabelece contato visual. Ou seja,já está presente o contato visual no nascimento, que favorece a interação social entre bebê e mãe.

O contato visual entre mãe e bebê é um argumento que se tem hoje para comprovar que esta condição chamada autismo: distúrbio do desenvolvimento da cognição causado por lesões no cérebro é consciência. Isto é, o indivíduo nasce autista, ele não fica autista depois (SCHWARTZMAN, 2003). "Existem muitas etiologias, tais como a genética, acidentes pré ou perinatais, infecções, e, em 25\% - $40 \%$ dos casos, o autismo está ligado a outras síndromes neurológicas" (NILSSON, 2003, p. 23). Desse modo, quase toda criança com esta condição, em qualquer nível de inteligência, precisa de ajuda com planejamento, pois é muito difícil para a criança autista ter empatia e, para ela, o mundo social é muito confuso (BARON-COHEN, 2003).

A interação tátil entre mãe e bebê também tem um enorme significado nos processos precoces de comunicação certamente inscritos e projetados no desenvolvimento emocional da criança, cujo paradigma antagônico é ilustrado nas crianças autistas, em que a intensa sincronização entre os dois protagonistas é inexistente (FONSECA, 1998).

Então, como entrar em contato com uma criança autista? Para poder estabelecer um contato com o outro ser e abrir algum canal de comunicação surge à necessidade de imitar o outro, ou de fazer algo igual ao outro com quem pretendemos entrar em contato. Em se tratando da criança autista, é necessário imitar alguns sons que ela emite (BENZENON, 1988). É necessário também que as pessoas que a circundam tenham tolerância e a valorizem, do contrário, estas pessoas podem levá-la a problemas graves, até mesmo a destruição de sua vida social (BARON-COHEN, 2003). Ninguém me- lhor do que a mãe para exercer este papel: esta ajuda planejada.

Entre duas e doze semanas, a criança normal olha os objetos fixando-os, já fixa claramente a face da mãe, e segue alguns objetos com o olhar. Aos três meses, coloca as mãos em frente aos olhos. Não necessariamente porque melhorou a visão, mas porque nesta fase de idade algo já se começa a firmar em atitudes simétricas. $\mathrm{E}$ as suas mãozinhas podem ser colocadas à frente do rosto e na linha média do corpo. Entre três e quatro meses, reage ao seu reflexo no espelho. Mostra interesse por outras crianças. Meninas, mais do que meninos. Parece que já há uma diferença atuando quanto à empatia e à competência social, e depois marca a diferença entre os sexos, já na criança pequena.

Esta evolução continua até chegar aos padrões que o ser humano considera como do adulto. A acuidade visual (grau de pormenores que podem ser observados em um objeto), por exemplo, aumenta rapidamente a partir do nascimento. No nascimento é menor que $6 / 24 \mathrm{~m}$. e à medida que o tempo vai passando, rapidamente ela chega aos 6/6 m., que é o padrão normal do adulto, adquirida por volta dos dois anos. A criança pequena não tem acomodação: a capacidade de fixar objetos em diferentes distâncias, permitindo ao cristalino a habilidade de cada olho variar sua curvatura a fim de acomodar a imagem na retina em um foco preciso. De modo que seu foco visual é muito limitado. Ela enxerga relativamente bem objetos colocados a 20 e 30 centímetros do seu rosto. E, coincidentemente, é a distância que vai do seu rosto quando mama no peito ao rosto da mãe. Desse modo, parece ser um sistema que já esteja pronto. Em suma, sua visão é nublada ao nascimento, melhorando até a idade de dois anos.

\section{O comportamento auditivo}

Com o comportamento auditivo é a mesma história. Ao nascer, o bebê já tem quase um 
ano de vida, dos quais boa parte em ambiente altamente sonoro. Costumamos dizer que provavelmente o ambiente uterino seja gostoso, morno e silencioso. Ele pode ser tudo, menos silencioso, porque é um ambiente que reverbera o som biológico da mãe, transmitido pelo líquido amniótico, de modo que o bebê está constantemente exposto aos batimentos cardíacos da mãe, aos ruídos intestinais, aos atritos, ao movimento e à sua voz. Desse modo, após algumas horas do nascimento o bebê reage de forma diferenciada à voz da mãe em relação à voz de outra mulher. É provável que o bebê já tenha a voz da mãe como modelo de voz mais ouvida, assim como a percepção de seu cheiro e dos batimentos do seu coração.

Até aos seis meses a audição do bebê se manifesta claramente pela presença de vários reflexos: o cócleo-palpebral, por exemplo, é o reflexo pelo qual um som intenso faz a criança fechar os olhos; ela reage ao som com clara resposta motora de sobressalto, talvez, a mais habitual. Outro exemplo, frente a um barulho alto, ele tenta colocar as mãos nas orelhas; altera a sucção, isto é, seu ritmo e potência frente a certos estímulos auditivos. As pesquisas mostram que a criança mama mais tranqüila e acalma seu choro mais facilmente do lado do peito onde sente os batimentos cardíacos da mãe; mais ainda: as últimas investigações confirmam que os movimentos rítmicos de sucção do recém-nascido estão em íntima relação com seus próprios batimentos cardíacos, ou seja, que se aceleram os batimentos cardíacos de um bebê quando se acelera o seu ritmo de sucção e vice-versa, assim, ele cresce desenvolvendo seus próprios ritmos corporais em dueto com a mãe, que o alimentava desde o útero: o ritmo cardíaco, a respiração, os movimentos e as vibrações da voz materna (MATURANA; VERDEN-ZÖLLER, 2004); apresenta tremores e pode apresentar um reflexo de Moro exacerbado.

É uma reação corporal maciça subseqüente ao sobressalto determinado por vários estímulos, que têm em comum a particularidade de in- duzir uma extensão da cabeça, alterando sua relação com o tronco. Consiste na extensão, abdução e elevação de ombros superiores; seguida de retorno à habitual atitude flexora em adução (CORIAT, 1991, p. 34).

Logo após o final do terceiro mês de vida o bebê começa a localizar posições. De início lateralmente; depois, à frente e atrás. À medida que vai ficando mais velho, responde de forma diferente aos sons. Entre zero e dois meses, ele desperta do sono com um som de 90 decibéis. Entre três e quatro meses já evidencia um movimento rudimentar da cabeça em direção ao som quando ele não é muito intenso.

Entre quatro e sete meses o bebê já localiza claramente a fonte sonora no sentido lateral, mas ainda não localiza no sentido posterior. Aos sete e nove meses localiza a fonte sonora diretamente à frente. Entre nove e treze meses localiza a fonte sonora para os lados e para baixo. Daí para frente ele localiza a fonte sonora qualquer que seja a sua origem.

O desenvolvimento continua até ao final do segundo ano de vida. E, passo a passo, ocorre de forma setorial, não linear, é irregular, sem sincronia, contínuo na sua dimensão quantitativa (grau e freqüência) e descontínuo na sua dimensão qualitativa (mudanças estruturais ou organizacionais) (BARELA, 2003).

\section{A linguagem}

Outro dado fundamental é o desenvolvimento da linguagem. Já no nascimento a criança reage de forma clara a determinados sons da fala. Dá algumas respostas motoras: movimentos corporais amplos, quando sinalizamos com objetos. À medida que o tempo vai passando, rapidamente ganha a possibilidade de comunicação não-verbal, depois a verbal. Por volta de um ano e três meses, brinca com os sons da fala. Os bebês do sexo feminino parecem ser geneticamente inclinados a falar mais cedo que os do sexo masculino. Entretanto, as áreas do cérebro do bebê ligadas à 
linguagem só se desenvolvem por completo se alguém conversar com ele.

O aumento do vocabulário é enorme, principalmente quando a criança vive em um ambiente que a linguagem é usada com freqüência. A linguagem é uma das habilidades, altamente sensível ao bem interno.

Os fatores ambientais aumentam imensamente as capacidades genéticas. Segundo Schwartzman (2003), as meninas falam antes, falam melhor e nunca mais calam a boca. Nascem com uma vantagem na maturação de $10 \%$ sobre os meninos. As meninas, ao nascimento, têm uma idade óssea que antecede à dos meninos em três a quatro semanas em média. Os meninos são mais propensos a dislexias, disgrafias, discalculias, gagueira, autismo, deficiência mental.

Então, como é que podemos saber, além dessas coisas que são relativamente fáceis de serem observadas, o que os bebês realmente sabem? E aí temos que tomar cuidado, porque as armadilhas nas quais vários pesquisadores caíram é que eles colocavam os bebês frente a um determinado estímulo, viam que respostas eles davam, e como eles não davam uma resposta motora que revelasse claramente que eles haviam realizado a tarefa, o pesquisador generalizava como falta de intencionalidade ou por não ter atingido tal estágio de desenvolvimento etc., esquecendo que o bebê ainda não tinha a condição daquela resposta.

Isto mudou à medida que se modificaram as possibilidades de avaliação das respostas dos bebês. Por exemplo, a reação dos bebês a determinados estímulos realizados em laboratório, utilizando resposta de aferição visual, mostrou que os bebês têm um grau de alerta visual devido à quantidade de olhares em determinadas coisas: rosto da mãe, por exemplo, bem como revelam interesse pelas novidades e as olham por muito mais tempo em um campo em branco de contraste. Então, o que concluímos? A tendência das crianças para olharem o padrão de referência pelo rosto da mãe, a preferência por um campo em bran- co de contraste e a preferência pela novidade são provadas no nascimento (SCHWARTZMAN, 2003).

Vamos tentar explicar isto, usando dois paradigmas: o da articulação e o da desarticulação. O que é isto? Sabemos que o bebê prefere um padrão a um campo em branco de contraste. A hora que se projeta um padrão em um campo em branco de contraste, se desperta o interesse no bebê. Ele revela isto, olhando de modo fixo para o objeto. À medida que esta experiência se repete, com o mesmo estímulo, cai o interesse devido à habituação: processo no qual a atenção da criança à novidade diminui com a exposição a um estímulo. Se neste momento for introduzido um novo padrão de estímulo, se desperta novo interesse visual devido à desabituação: processo no qual o interesse do bebê é renovado após a mudança de estímulo. Desse modo, temos um mecanismo de articulação que comprova que ele já se cansou daquele estímulo e temos um de desarticulação que nos permite saber que o bebê identifica características diferentes no novo padrão (SCHWARTZMAN, 2003).

São estas experiências que nos permitem fazer algumas inferências tais como: a tendência ao olhar confirma o que o bebê quer; o que ele não quer; e, o que pensa ser novo ou não. São estas ações que vão afetar sua interação com o ambiente, que vão envolver sua orientação espacial, ou seja, as crianças olham para estímulos novos, manifestando a presença de orientação espacial desde o nascimento; os bebês preferem olhar faces a objetos e isto pode ser constatado a partir das primeiras horas de vida. Esta predileção, segundo Johnson (1992), é dada pelo equipamento biológico; contudo, não podemos esquecer o grau de interação social mãe-bebê, a imitação, o olhar, o sorriso e a maternagem.

Um conselho para quem trabalha com bebês: mantenha vivo o bebê que existe em você. É de fundamental importância se manter ao nível do bebê. Para entrar em comunicação com um bebê, nada melhor do que 
balbuciar para ele e com ele. Por outro lado, o bebê também tratará de imitar parâmetros simples da nossa linguagem.

Uma experiência realizada por Meltzoff e Moore (1994), citada por Cole e Cole (2003), em que um adulto parado diante de bebês recém-nascidos acordados fazia diferentes expressões faciais, tais como abrir muito a boca e colocar a língua para fora, relata que os bebês imitam freqüentemente a expressão facial do adulto. Bem, isto não é reflexo, não é coincidência, não é alguma coisa ao acaso. Isto é algo que o ser humano não consegue explicar. Então, perguntamos: como é que esse bebê sabe que esse pedaço do corpo do adulto é igual ao que ele projeta para fora? $\mathrm{E}$ as nossas teorias sobre esquema corporal começam a balançar. Ou seja, esta criança já tem parte do esquema corporal de sua bagagem genética. Ela não o adquiriu até o momento. Obviamente, vai aprimorá-lo com ajuda do ambiente. Então, isto põe em xeque a idéia de que o bebê não tem estrutura cortical funcionando (SCHWARTZMAN, 2003).

As crianças já nascem com a possibilidade ilimitada de modificar em si e nas outras pessoas algumas estruturas. Por exemplo: o sugar é um aprendizado que induz a novas formas de sucção, assim como o pegar, o ver, o ouvir, o perceber e o agir, que vão se aperfeiçoando até formarem as aquisições básicas de motricidade, linguagem, competência social e cognição.

Nesse sentido, a participação ativa do ser em desenvolvimento, no caso o bebê, é essencial para o desenvolvimento do processo. Ou seja, a aquisição de uma determinada habilidade motora e seu aperfeiçoamento é específica ao contexto no qual este processo ocorre. Em outras palavras, este processo de aperfeiçoamento, esclarece Barela (2001), é fruto de repetições da tarefa que propiciaram ciclos correspondentes de ação e percepção da ação realizada com referência ao objetivo de realização da tarefa. Em resumo, o processo de desenvolvimento é influenciado por um conjunto de fatores, ou seja, de restrições do organismo, do ambiente e da tarefa, que traçam o caminho e a velocidade desse processo de desenvolvimento. Dessa forma, as mudanças no desenvolvimento ocorrem devido a alterações em uma ou mais restrições que levam à emergência de um novo comportamento no bebê, mediante a exploração do ambiente e seleção da tarefa. No caso de crianças deficientes, o incentivo a esta exploração e seleção pelo adulto torna-se fundamental, porque uma criança limitada em seu espaço de ação por um impedimento físico, sensorial ou intelectual, terá dificuldades de estabelecer um elo com o mundo, mediante aprendizagem. Intervir neste espaço de ação se faz necessário. É o papel da intervenção precoce - conjunto organizado de estímulos e treinamentos adequados oferecidos nos primeiros anos de vida a crianças já identificadas como deficientes e àquelas de alto risco, de modo a lhes garantir uma evolução tão normal quanto possível (FARIAS, 1995, p. 2).

As crianças são cientistas no berço: fazem fortes desafios a respeito do ambiente que estão inseridas. E, as hipóteses são confirmadas ou não de acordo com a notificação do comportamento circunstante que envolve objetos, pessoas, eventos e situações: o que acontece se choro? O que acontece se faço determinada coisa? Ela já tem uma clara idéia de que suas atitudes podem levar a modificação do ambiente que a circunda.

O paradigma da habituação e da desabituação pode nos ajudar a esclarecer esses desafios vivenciados no ambiente pelo bebê cientista. Por exemplo: se colocarmos uma criança de três meses e meio em uma relativa situação impossível, tendo ela habituado a uma situação possível. Imaginamos que ela vá ficar mais alerta quando o inusitado aparecer, como um episódio de mágica: habituação ao esperado e uma resposta ao inusitado. Não sabemos o que a criança pensa, mas fica clara sua interrogação e sua cara de surpresa. Imaginamos que a criança se comporta como nós num espetáculo de mágica: o impossível acontece 
à sua frente e ficamos indagando como pode acontecer. Esse resultado nos leva a refletir que ao contrário do que afirma Piaget (1973) de que os bebês não têm a percepção dos objetos ocultos, isto é, se retirado um objeto de sua frente ele não o procura. Os bebês de três meses e meio de idade já apresentam a existência de objetos ocultos.

\section{Sobre as janelas da aprendizagem}

"Período crítico é um período no qual o indivíduo é mais susceptível a determinada influência externa, maximizando os efeitos dos estímulos ambientais" (BARELA, 2003, p. 9). A questão é: a criança aprende após um período crítico? Sim. Só que com mais dificuldades. As janelas não são rígidas. Idosos poderão aprender uma nova língua. Terão mais dificuldades, mas aprenderão. Contudo, se você não aprender a linguagem falada até o final do sexto e sétimo aniversário, dificilmente você aprenderá. Mas isto não quer dizer que você deverá aprender diferentes línguas até este período. É preciso cautela com as janelas de aprendizagem. Existem períodos críticos de aprendizagem. Para algumas habilidades elas são fundamentais. Por exemplo: se não for operada a catarata congênita até o final do sexto ano de vida, provavelmente este indivíduo ficará cego pelo resto da vida. Por quê? Porque ao que se refere à visão, embora o ser humano nasça com todo o sistema ocular pronto para enxergar, se esse olho, retina e córtex não receberem estímulo eles deixam de funcionar. É o sistema que vem preparado, mas que tem que ser formatado pelo ambiente. Logo, no caso da visão, o período crítico é óbvio (SCHWARTZMAN, 2003).

O que temos que levar em consideração é que cada aprendizado altera a estrutura física do cérebro. Cada novo aprendizado implica em alguma alteração estrutural no cérebro. "Os genes podem dar o potencial de inteligência. Mas é preciso haver um estimulo do ambiente para silenciar ou não os genes e moldar a arquitetura do cérebro" (VERNY,
2004, p. 28). A vivência social desenvolve o córtex terciário. E para se apropriar da cultura social envolvente, a criança necessita de mediação adequada. O desenvolvimento das aquisições básicas de motricidade, linguagem, competência social e cognição surgem somente quando a criança tem um envolvimento apropriado, resultado de vários fatores neurobiológicos: mielinização, crescimento dendrítico, crescimento dos corpos celulares, estabelecimento de circuitos interneuronais e muitos outros eventos bioquímicos, mas eles só se complexificam num envolvimento humano e cultural adequado (FONSECA, 1998). Em suma,

tudo que a criança experimenta desde a concepção constrói seu corpo. Isso inclui o cérebro. Só é possível construir um "bom" cérebro quando está conectado a outro ser humano. É muito importante para os pais começarem a se relacionar com os filhos desde a concepção. A arquitetura do cérebro depende dos estímulos (VERNY, 2004, p. 32).

Segundo Schwartman (2003), o mito que tem que cair por terra é a história de que quanto mais neurônios e quanto mais sinapses você tiver, mais inteligente você fica. Não é assim. Segundo o autor, nós temos que ter quase metade dos neurônios com os quais nascemos. Para ele, o período que nós temos maior número de neurônios por milímetro no cérebro é entre dois e quatro anos de idade. A partir dessa idade, entra em processo o que se chama morte do neurônio, que você tem que destruir os neurônios inoperantes para que os outros funcionem bem. $\mathrm{Na}$ verdade, o cérebro em desenvolvimento implica produção de neurônios, produção de sinapses e depois o que o gênero humano chama de poda de neurônios e poda de sinapses. Se você não poda, isto não te torna mais inteligente. Por exemplo, indivíduos com Síndrome de Down em determinadas regiões do cérebro têm mais neurônios e mais sinapses do que pessoas normais. $\mathrm{O}$ cérebro precisa de um 
número ótimo dessas estruturas. A modificação estrutural do cérebro frente ao aprendizado é de tal ordem que o cérebro a cada dia é totalmente diferente do que foi no dia anterior. E nós podemos afirmar que o cérebro do bebê também difere de um dia para outro. E o curioso dessa história é que se mantém uma identidade. Muda muita coisa, mas não muda algo de fundamental, que é a consciência de cada um. Instrução e aprendizado são fundamentais para o desenvolvimento cerebral (SCHWARTZMAN, 2003).

O desenvolvimento cerebral e psicológico envolve uma interação saudável entre o indivíduo e o meio ambiente. O desenvolvimento da criança só é possível pela mediatização do adulto. Só dentro de um processo de comunicação, primeiro afetivo e motor, e depois emocional e verbal, é que podemos entender o desenvolvimento global da criança. $\mathrm{O}$ adulto é quem facilita inteligentemente o uso da mão, da voz e das atitudes da criança. São as condutas do adulto (na família, principalmente) que vão garantir a segurança do crescimento e do desenvolvimento da criança. Uma melhor compreensão da natureza desse processo interativo é que vai nos possibilitar responder de uma forma mais adequada qual o papel desempenhado pelos genes e pelo ambiente. Ambos são fundamentais ao processo de desenvolvimento. Segundo Schwartzman (2003), tentar privilegiar um mais que o outro é como querer provar quem contribui mais para a área do retângulo: se a altura ou a largura. A genética contribui para com o ambiente e vice-versa. Devemos torcer por genes saudáveis, bem como por um ambiente adequado, não esquecendo o papel da cultura nesse processo.

\section{What do babies know? A different approach to thinking about them}

\footnotetext{
Abstract

The aim of this article is to present a different approach to thinking about babies as both reflex and cortical hu-
}

man beings who are motivated to communicating with others; who react to light, sound, and their mother's voice; who feel and know they exist from as early as their $24^{\text {th }}$ week of pregnancy.

Keywords: baby - intersubjectivity - mind theory - visual and listening behavior - language and learning

Qué saben los bebés? Un modo diferente de pensarlo

\section{Resumen}

El objetivo de este artículo es presentar un modo diferente de pensar el bebé: un ser que reflexiona, sin embargo cortical también, que se encuentra motivado para la comunicación con los otros, que reacción ante luz, al sonido y a la voz de la madre; que siente y sabe que existe al final del segundo trimestre de la gestación.

Palabras-clave: bebé - teoría de la mente - comportamiento visual, auditivo - lenguaje y aprendizaje

\section{Agradecimento}

Este artigo tem o apoio da Fundação Carlos Chagas Filho de Amparo à Pesquisa do Estado do Rio de Janeiro da Secretaria do Estado de Ciência e Tecnologia (FAPERJ), sob a concessão de bolsa E-26/151.240/2002, em parceria com o Programa de Pós-Graduação em Educação da Universidade do Estado do Rio de Janeiro (UERJ). A estas instituições e orientadora, meus agradecimentos.

\section{Referências}

BARELA, J. A. Ciclo percepção-ação no desenvolvimento motor. In: TEIXEIRA, L. A. Avanços no comportamento motor. São Paulo: Movimento, 2001. p. 40-61.

- Aprendizagem e desenvolvimento motor: introdutório. Caxambu: XIII COMBRACE, 2003. p. 1-10.

BARON-COHEN, S. The essential difference: the truth about the male and female brain. Cambridge: Mass., MIT Press, 2003.

BENZENON, R. Teoria da musicoterapia: contribuição ao conhecimento do contexto não verbal. São Paulo: Summus, 1988. 
BERGER, K. S. The developing person: through childhood and adolescence. New York: Worth Publishers, 2000.

BRONOWSKY, J. The ascent of man. Boston: Little Brown, 1986.

COLE, M.; COLE, S. R. O desenvolvimento da criança e do adolescente. Porto Alegre: Artmed, 2003.

CORIAT, L. F. Maturação psicomotora no primeiro ano de vida da criança. São Paulo: Moraes, 1991.

FARIAS, G. C. Efeitos de um programa de estimulação desenvolvido mediante uma linha de base múltipla para uma aluna cega. Monografia apresentada no Curso de Especialização da Escola Superior de Educação Física do Estado de Goiás, 1995.

FIAMENGHI, G. J. Emoções e motivação. São Paulo: Memnon Edições Científicas, 2003.

FONSECA, V. Psicomotricidade: filogênese, ontogênese e retrogênese. Porto Alegre: Artes Médicas, 1998.

GALLAHUE, D. L.; OZMUN, J. C. Compreendendo o desenvolvimento motor: bebês, crianças, adolescentes e adultos. São Paulo: Phorte, 2003.

JOHNSON, G. In the places of memory. Nova York: Vintage Books, 1992.

LEWIS, T.; AMINI, F. e LANNON, R. $A$ general theory of love. Vintage: EUA, 2001.
MATURANA, H.; VERDEN-ZÖLLER, G. Amar e brincar: fundamentos esquecidos do humano. São Paulo: Palas Athenas, 2004.

NILSSON, I. A educação de pessoas com desordens do espectro autístico e dificuldades semelhantes de aprendizagem. Temas sobre Desenvolvimento, São Paulo, v. 12, n. 68, 2003. p. 5-45.

NUNES, L. R. Métodos naturalísticos para o ensino da linguagem funcional em indivíduos com necessidades especiais. In:

(Org.). Novas contribuiçôes da psicologia aos processos de ensino e aprendizagem. São Paulo: Cortez, 1992. p. 71-96.

PIAGET, J. Biologia e conhecimento: ensaio sobre as relações entre as regulações orgânicas e os processos cognoscitivos. Petrópolis: Vozes, 1973.

PINKER, S. Como a mente funciona. São Paulo: Companhia das Letras, 2001.

SCHWARTZMAN, J. S. Neurologia da infância e adolescência. São Paulo: Memnon Edições Científicas, 2003.

VERNY, T. Bebês do amanhãa: arte e ciência de ser pais. São Paulo: Millenium, 2004.

Recebido: 14 de novembro de 2007

Aprovado: 29 de fevereiro de 2008

Endereço para correspondência polianajr@uol.com.br 